\title{
CSF Biomarkers for Alzheimer's Disease Diagnosis
}

\author{
A. Anoop, Pradeep K. Singh, Reeba S. Jacob, and Samir K. Maji \\ Department of Biosciences and Bioengineering, IIT Bombay, Powai, Mumbai 400076, India \\ Correspondence should be addressed to Samir K. Maji, samirmaji@iitb.ac.in
}

Received 15 March 2010; Accepted 27 April 2010

Academic Editor: Lucilla Parnetti

Copyright ( 2010 A. Anoop et al. This is an open access article distributed under the Creative Commons Attribution License, which permits unrestricted use, distribution, and reproduction in any medium, provided the original work is properly cited.

\begin{abstract}
Alzheimer's disease (AD) is the most common form of dementia that affects several million people worldwide. The major neuropathological hallmarks of $\mathrm{AD}$ are the presence of extracellular amyloid plaques that are composed of $\mathrm{A} \beta 40$ and $\mathrm{A} \beta 42$ and intracellular neurofibrillary tangles (NFT), which is composed of hyperphosphorylated protein Tau. While the amyloid plaques and NFT could define the disease progression involving neuronal loss and dysfunction, significant cognitive decline occurs before their appearance. Although significant advances in neuroimaging techniques provide the structure and physiology of brain of AD cases, the biomarker studies based on cerebrospinal fluid (CSF) and plasma represent the most direct and convenient means to study the disease progression. Biomarkers are useful in detecting the preclinical as well as symptomatic stages of AD. In this paper, we discuss the recent advancements of various biomarkers with particular emphasis on CSF biomarkers for monitoring the early development of $\mathrm{AD}$ before significant cognitive dysfunction.
\end{abstract}

\section{Introduction}

Alzheimer's disease $(\mathrm{AD})$ is the most widespread neurodegenerative disease globally [1] and is estimated to afflict more than 27 million people worldwide [2]. AD accounts for at least $60 \%$ of all dementia diagnosed clinically. The major pathological hallmarks of $\mathrm{AD}$ are the loss of neurons, occurrence of extracellular senile plaques as well as intracellular neurofibrillary tangles (NFT) [3]. Senile plaques are primarily composed of amyloid $\beta$-protein $(\mathrm{A} \beta)$, which is produced from the amyloid precursor protein (APP) by sequential proteolytic cleavages made by two proteolytic enzymes, $\beta$-secretase $(\beta$-site APP-cleaving enzyme; BACE) and $\gamma$-secretase (Figure 1) [4]. Amyloid plaque is an aggregate of $\mathrm{A} \beta$ containing $40-42 / 43$ residues. NFT is primarily composed of hyperphosphorylated form of Tau protein [5]. Tau is synthesized within the neuron and localized in the axon where it promotes stability and assembly of microtubules [6]. During AD progression, tau is hyperphosphorylated and subsequently dissociated from microtubule and polymerized into paired helical filaments (Figure 1) [5, 6]. Although the clinical symptoms of AD are frequently diagnosed in older age, the degenerative process probably starts many years before the clinical onset of the disease $[7,8]$. Currently, the diagnosis and treatment of $\mathrm{AD}$ is limited. The presymptomatic detection of $\mathrm{AD}$ is crucial, as it would facilitate the development of an efficient and rapid treatment of this destructive disorder early on (for recent review see $[9-11])$.

The biomarkers are the entities whose concentration, presence, and activity are associated with disease. Biomarkers are essential part of disease treatments as they are essential for diagnosis, monitoring the disease progression, detecting early onset of the disease, monitoring the effect of therapeutic intervention, and also avoiding false diagnosis of the disease [19]. An ideal biomarker (1) should be highly specific, (2) should predict the course of illness accurately, and (3) should reflect the degree of response to treatment. The biomarker research for $\mathrm{AD}$ has significantly advanced in recent years (Table 1) [9, 10]. The neuroimaging techniques assess the regional structure and function of the brain, as well as assist identifying the biochemical profile of brain dysfunction. The body fluids such as cerebrospinal fluid (CSF), plasma, and urine are considered as important sources for the AD biomarker development (Table 1). CSF is considered a better source for biomarker development as it is in direct contact with the extracellular space of the brain and can reflect biochemical changes that occur inside the brain. 
TABLE 1: Some promising biomarkers in diagnosis of AD.

\begin{tabular}{|c|c|c|c|c|}
\hline Category & Markers & Advantages & Limitations & References \\
\hline \multirow{4}{*}{ Imaging } & & (1) Noninvasive & (1) Expensive & \multirow{4}{*}[12-14]{} \\
\hline & CT, PET, PIB-PET, & (2) Provides structural and functional & (2) Requires experienced personnel & \\
\hline & MRI & details of brain immediately & (3) The sensitivity and specificity to & \\
\hline & & (3) Can reveal disease progression & $\mathrm{AD}$ is not satisfactory & \\
\hline \multirow{3}{*}{ Plasma } & $\alpha_{2}$-Macroglobulin, & (1) Noninvasive & (1) Less correlation to AD & \multirow{3}{*}[15-17]{} \\
\hline & Complement & (2) Samples are easily accessible & (2) Less sensitive and specific for AD & \\
\hline & factor $\mathrm{H}, \mathrm{A} \beta 42$ & & diagnosis (due to epitope masking) & \\
\hline \multirow{4}{*}{ CSF } & $\mathrm{A} \beta 42, \mathrm{t}-\mathrm{tau}$ & (1) Can correlate AD directly & (1) Invasive, sample has to be collected & \multirow{4}{*}[10,18]{} \\
\hline & $\mathrm{p}$-tau p-tau/A $\beta 42$ & (2) Highly sensitive and specific & by lumbar puncture & \\
\hline & $\mathrm{t}-\mathrm{tau} / \mathrm{A} \beta 42$ & (3) Can detect $\mathrm{AD}$ progression & (2) Irreproducible diagnosis due to & \\
\hline & & & sample storage and transportation & \\
\hline
\end{tabular}

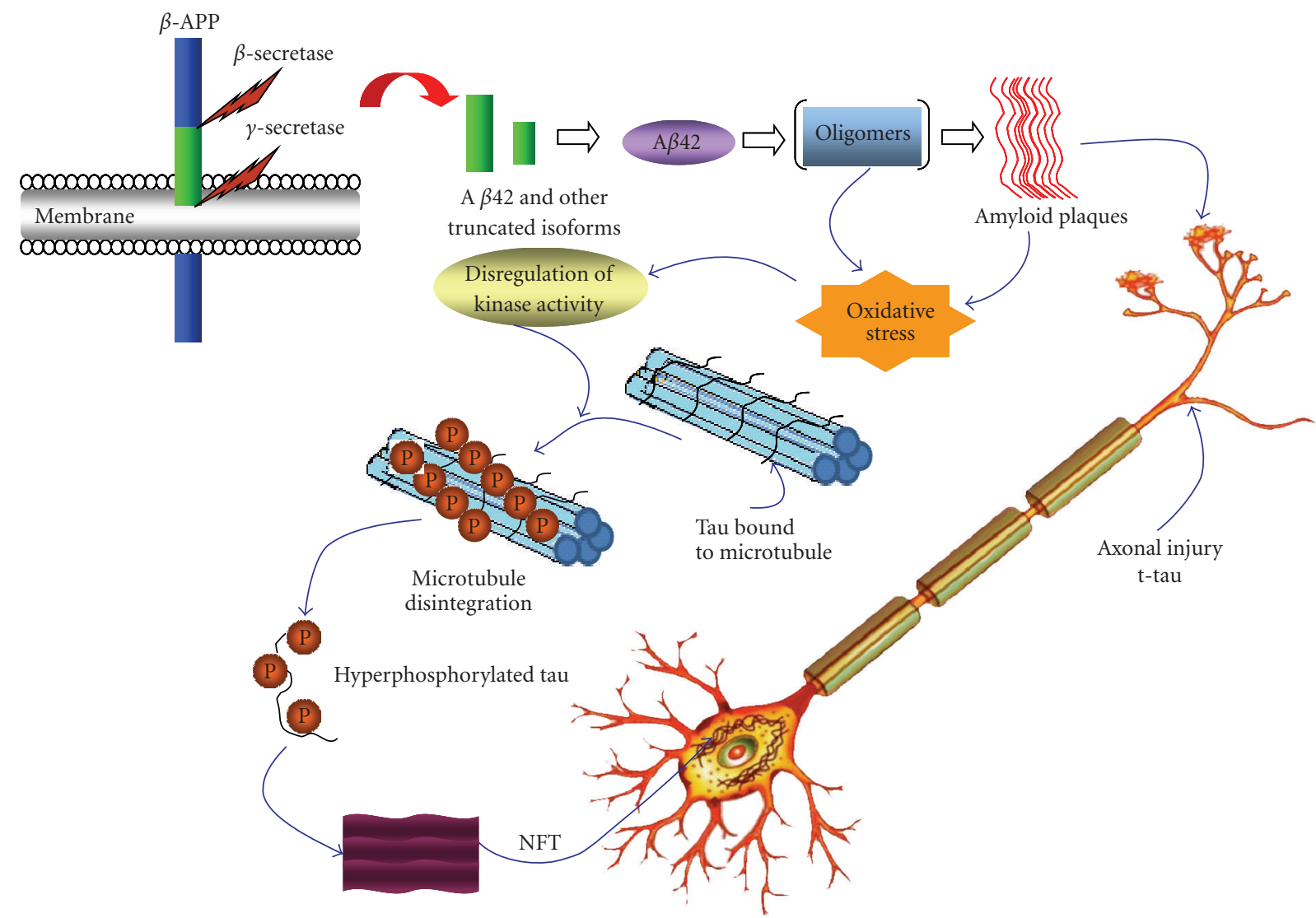

FIGURE 1: Pathological cascades and potential biomarkers of AD. Proteolytic cleavage of APP first by $\beta$-secretase followed by $\gamma$-secretase can produce $\mathrm{A} \beta 42$ and other shorter $\mathrm{A} \beta$ fragments. The subsequent aggregation of $\mathrm{A} \beta 42$ results in oligomers and amyloid fibrils. Amyloid fibrils are eventually deposited as senile plaques as shown. The toxicity of oligomers and amyloid fibrils could lead to the cascade of tau-hyperphosphorylation, which is otherwise bound to microtubules, providing microtubule stability. Upon hyperphosphorylation, tau dissociates from microtubules and aggregates into NFT, which could eventually cause increased cytoskeleton flexibility and neuronal death.

Thus far, three CSF biomarkers, A $\beta 42$, total-tau (t-tau), and phosphorylated-tau ( $\mathrm{p}$-tau), have been found to have the highest diagnostic potential. Biomarkers of inflammation and oxidative stress and urine-based biomarkers are among the other sources that provide vital information on development and progression of AD. Unfortunately, none of the biomarkers presently available are able to accomplish the disease diagnosis single-handedly. Monitoring more than one biomarker at the same time is suggested to be suitable for detecting the disease progression. The main focus of this paper is to provide insights on the various potential biomarkers with particular emphasis on CSF biomarkers for $\mathrm{AD}$ diagnosis. These biomarkers are very promising for early diagnosis of $\mathrm{AD}$. 


\section{Imaging Biomarkers}

Neuroimaging techniques provide structural and functional details of the brain immediately $[20,21]$. The imaging techniques are also helpful to predict and monitor the disease progression. Recent progress of functional and molecular neuroimaging [22] could provide insights into brain structure and physiology and also could detect the specific proteins and protein aggregates due to $\mathrm{AD}$ in the brain [20].

The loss of brain volume is one of the consequences of $\mathrm{AD}$ neurodegeneration $[11,21]$, and it could be differentiated from normal brain by using computerized tomography (CT) and magnetic resonance imaging (MRI) techniques [23]. These techniques are able to show neuronal loss, atrophy of medial temporal regions, as well as neurofibrillary tangles in the brain of $\mathrm{AD}$ patients. Using MRI technique, it is now possible to distinguish atrophy during early stage of $\mathrm{AD}$ from the atrophy of normal aging [24]. MRI has also the ability to distinguish $\mathrm{AD}$ subjects from normal controls, with a very high sensitivity and specificity [24]. MRI can reveal disease progression from cognitive normalcy to mild cognitive impairment (MCI) and to $\mathrm{AD}$ [12]. Discrimination of AD from other forms of dementia, namely, frontotemporal dementia (FTD) and DLB (dementia with Lewy bodies) is also possible based on different atrophy patterns that MRI reveals [25-27]. AD is also associated with metabolic impairment with typical regional pattern in the brain and could be detected by positron emission tomography (PET). If 18F-2-deoxy-2-fluoro-D-glucose (FDG) is chosen for PET, the concentrations of tracer imaged then gives tissue metabolic activity, in terms of regional glucose uptake. PET-FDG has been employed to examine regional cerebral metabolism, which is helpful in distinguishing $\mathrm{AD}$ from normal patients $[13,28-30]$. Recently, several other radiologically contrast compounds have been developed for PET imaging, which could bind the pathological structures such as amyloid plaques, NFT, activated microglia, and reactive astrocytes, enabling the examination of antemortem pathological changes due to AD. The compounds that have been reported as probes for amyloid plaques in PET imaging include, $[18 \mathrm{~F}]$ FDDNP (2-(1-\{6-[(2-[F-18] fluoroethyl) (methyl) amino]-2-naphthyl\} ethylidene) malononitrile), 18F-BAY94-9172, 11C-SB-13, 11C-BF-227, and 11C-PIB. The only compound developed that can bind NFT in vivo is [18F] FDDNP. The 11C-PIB (PIB, Pittsburgh compound $\mathrm{B})$ has been the most extensively studied and applied in $\mathrm{AD}$ research $[14,31]$. In individuals with $\mathrm{AD}$, increased retention of PIB shows a very specific pattern that is restricted to brain regions (frontal, parietal, temporal, occipital cortices, and striatum), typically associated with amyloid deposition [32]. A significant number of cognitively normal individuals over the age of 60 show a PIB signal pattern indistinguishable from that of individuals with $\mathrm{AD}$, suggesting that measurement of PIB using PET can detect a preclinical stage of the disease. When PIB-PET was performed along with the $\mathrm{A} \beta 42$ concentrations in CSF of $\mathrm{AD}$ patients, the PIBpositive group showed low $\mathrm{A} \beta 42$ levels in the cerebrospinal fluid [33-35]. This finding is consistent with the "amyloid sink" hypothesis [36, 37], according to which the soluble $\mathrm{A} \beta 42$ is retained in the brain once plaques are formed. Besides the radiological studies of amyloid plaques and NFT, the PET imaging agent which images the inflammation due to activated microglia and reactive astrocytes has been developed. For example, increased expression of peripheral benzodiazepine receptor (PBR) has been target for the compound [11C] (R)-PK11195. The study using this compound in conjunction with PIB has suggested that microgliosis occurs concomitantly with amyloid deposition and may have direct role in cognitive dysfunction [38]. Like microglia, the changes in astrocytes on association with plaques could be used as biomarkers. For example, using inhibitors of monoamine oxidase $\mathrm{B}$ as radiotracers in $\mathrm{AD}$ has targeted the elevation of monoamine oxidase B activity $[39,40]$. Although all of these imaging techniques are helpful for diagnosis of $\mathrm{AD}$, the approach faced overlapping symptoms due to other pathological processes and normal aging. The approach also needs expensive instruments and experienced personnel for its application in routine diagnosis of AD.

Fluid Biomarkers. The sampling of CSF and plasma represents the most direct and convenient means to study the biochemical changes occurring in the central nervous system $[10,19,41]$. These fluids are the most attractive resources for ongoing research for discovering $\mathrm{AD}$ biomarkers. Most of the research has been performed either with the plasma or CSF, yet CSF represents more suitable source for biomarker discovery.

\section{Plasma Biomarkers}

Plasma is the liquid portion of blood where red blood cells, white blood cells, and platelets are suspended. Plasma could be easily isolated from whole blood by low speed centrifugation in the presence of an anticoagulant. The easier sampling of blood plasma makes this fluid ideal for biomarker investigation. However, plasma biomarkers as reliable markers for $\mathrm{AD}$ have met little success (Table 1). Various blood biomarkers have been proposed, yet changes in the levels of these molecules have proved difficult to verify in independent studies. Multiple studies have identified plasma proteins whose expression levels in $\mathrm{AD}$ patients differ from controls. For example, $\alpha_{2}$-Macroglobulin $(\alpha 2 \mathrm{M})$ and complement factor $\mathrm{H}(\mathrm{CFH})$ showed an increased expression in $\mathrm{AD}$ subjects than in control [15]. Both of these proteins are shown to be present in senile plaques $[42,43]$. Similarly, the increased levels of $\alpha_{1}$-antitrypsin [44], $\alpha 1$-antichymotrypsin $[45,46]$, and decreased levels of Apolipoprotein A1 [47] in blood plasma/serum were observed in $\mathrm{AD}$ patients compared to healthy controls. Although these proteins may reflect pathological processes observed in $\mathrm{AD}$ and could differentiate diseased plasma compared to controls, these differences have yet to achieve sensitivity, specificity, and reproducibility. Irreproducibility might occur due to different analytical methodologies utilized in various laboratories, different choice of anticoagulant and depletion strategy, and storage related problems. The most popular plasma peptide utilized 
for biomarker research is $\mathrm{A} \beta$, which is the fundamental element of senile plaques in brain of AD patients [3]. Using ELISA, A $\beta$ can be detected in plasma. The findings from different studies have shown variable results. Some studies have suggested slightly higher $\mathrm{A} \beta 42$ or $\mathrm{A} \beta 40$ plasma levels in patients with $\mathrm{AD}$ than in controls [48]. However, most of the studies have found no change in plasma $\mathrm{A} \beta$ concentration between $\mathrm{AD}$ and healthy control [48]. It is also suggested that large $\mathrm{A} \beta 42 / \mathrm{A} \beta 40$ ratio could indicate the risk factors for $\mathrm{AD}$ [49]. These ambiguous results are probably explained by the fact that plasma $\mathrm{A} \beta$ is derived from peripheral tissues and does not reflect brain $\mathrm{A} \beta$ production. Furthermore, the hydrophobic nature of $A \beta$ makes the peptide bind to plasma proteins, which could result in "epitope masking" [16] and other analytical interferences. Recently, analysis of 18 plasma signaling and inflammatory proteins has accurately identified patients with $\mathrm{AD}$ and predicted the onset of $\mathrm{AD}$ in individuals with MCI [50]. However, further studies are required to analyze if this set of proteins is the best possible recipe of plasma biomarkers for preclinical $\mathrm{AD}$ diagnosis.

\section{Urine-Based Biomarkers}

Neural thread protein (NTP) levels have been consistently identified as an $\mathrm{AD}$ biomarker in urine [51, 52]. With disease severity, the urinary concentration of this protein increases. AD associated NTP (AD7c-NTP) in CSF also showed consistent results $[51,53]$. More research needs to be done to study the effects of AD7c-NTP levels upon therapeutic intervention [54-56]. Urinary F2-isoprostanes have been reported to be increased [54-56] or unchanged $[57,58]$, making them less reliable biomarkers. The utility of urine sample for $\mathrm{AD}$ diagnosis has advantage that sample collection is relatively easier and noninvasive compared to CSF and plasma. However, very low protein concentrations and high salt levels make it difficult to use urine sample as a source of biomarker [59].

\section{CSF Biomarkers}

Cerebrospinal fluid (CSF) is a translucent bodily fluid that occupies the subarachnoid space and the ventricular system around the brain. CSF acts as a "liquid cushion" providing a basic mechanical and immunological protection to the brain inside the skull and it can be obtained via lumbar puncture. Although lumbar puncture is invasive and potentially painful for the patient, CSF is probably the most informative fluid in biomarkers discovery for neurodegenerative disease prognosis [10]. CSF has more physical contact with brain than any other fluids, as it is not separated from the brain by tightly regulated blood brain barrier (BBB). As a result, proteins or peptides that may be directly reflective of brain specific activities as well as disease pathology would most likely diffuse into CSF than into any other bodily fluid. These proteins and metabolites can serve as excellent biomarkers of AD as well as other neurodegenerative diseases. In early course of $\mathrm{AD}$, for an example of MCI, when the correct diagnosis is most difficult, CSF biomarkers would be valuable in particular [10]. Tau and $A \beta$ in CSF represents the earliest and most intensively studied biomarkers [9, 10, 41, 60, 61]. Both proteins are linked to hallmark lesions of $\mathrm{AD}$, amyloid plaques, and neurofibrillary tangles. In the next section, we will discuss the clinical significance of $\mathrm{A} \beta$ and tau biomarkers in detail.

5.1. APP, $A \beta 40 / 42$, and Truncated $A \beta$ in CSF as Biomarkers. One of the major pathological features of $A D$ is the presence of senile plaques primarily composed of $\mathrm{A} \beta$, a proteolytic fragment of the amyloid precursor protein (APP) (Figure 1) [62]. The expression level of APP could serve as diagnostic markers in AD [61]. However, the experimental studies of APP expression level in CSF of AD patients are inconsistent [61]. The inconsistencies between studies ruled out the possibility of CSF-APP being a useful biomarker for $\mathrm{AD}$. APP is expressed in all tissues and could undergo cleavage by either $\alpha$-secretase or $\beta$-secretase to release sAPP- $\alpha$ or sAPP- $\beta$, respectively. The processing of APP by $\alpha$-secretase occurs via nonamyloidogenic pathway, and a reduced CSF level of $\operatorname{sAPP} \alpha$ in $\mathrm{AD}$ patients has been reported [63]. In contrast, APP processing first by $\beta$-secretase and subsequent digestion by $\gamma$-secretase leads to formation of $\mathrm{A} \beta$ (38-43 residues) peptides. The 42 -residue-long $A \beta$ isoform $(\mathrm{A} \beta 42)$ is highly hydrophobic and forms oligomers and fibrils that accumulate as extracellular plaques (Figure 1) [4]. Because $\mathrm{A} \beta 42$ is the dominant component of the plaques seen in $\mathrm{AD}$ [64], many groups have investigated the use of $\mathrm{A} \beta 42$, as well as the other $\mathrm{A} \beta$ species as a diagnostic tool. The amount of total $\mathrm{A} \beta$ in CSF is not well correlated with the diagnosis of $\mathrm{AD}[65]$. The majority of studies have demonstrated a decrease of CSF A $\beta 42$ in AD patients [34, 66-70]. However, few reports suggest the increased [71] or unchanged [72] CSF $\mathrm{A} \beta 42$ in $\mathrm{AD}$. These differences in observations might be due to the variations in sample assaying protocols and selection of patient groups. Deposition of the peptide in plaques ("amyloid sinks") is considered the underlying basis for the decrease of CSF-A $\beta 42$ levels seen in $\operatorname{AD}[36,37]$. Although it is not clearly proved, the observation is supported by the strong correlation between low CSF-A $\beta 42$ levels and high plaque burden when measured by PIB imaging [33]. This observation was further supported by the fact that $\mathrm{AD}$ mouse model showed low CSF A $\beta$ level with high amount of plaque in the brain [73]. Although it has been shown that CSF A $\beta 42$ levels can identify PIB-positive individuals with highest possible sensitivity and specificity, the decreased CSF levels of $\mathrm{A} \beta 42$ have also been reported in other dementia such as FTD [74-76]. Low concentrations of CSF A $\beta 42$ was also found with individuals without PIB-positive plaque [77]. This finding might be explained by the fact that PIB binds fibrillar $\mathrm{A} \beta$ not the $\mathrm{A} \beta$ oligomers or diffuse plaques [77] that are found in earlier stages of $\mathrm{AD}$ process. It is however that CSF A $\beta 42$ has high potential as a biomarker for diagnosis, plaque burden, prognosis and may provide clue of preclinical AD. $\mathrm{A} \beta 40$ is unchanged in the CSF of $\mathrm{AD}$ patients [21]. However, the decreased $\mathrm{A} \beta 42 / \mathrm{A} \beta 40$ ratio is much more pronounced in $\mathrm{AD}$ diagnosis than the 
reduction of $A \beta 42$ alone. Therefore, $A \beta 42 / A \beta 40$ ratio might be more useful in $\mathrm{AD}$ diagnosis in the early as well as the clinical phases of the disease [78]. Moreover, the presence of several shorter $A \beta$ isoforms in CSF has suggested that $A \beta$ constitutes a large family of peptides with considerable length variations. The carboxy-terminal truncated $\mathrm{A} \beta$ peptides for example, $A \beta 37, A \beta 38$, and $A \beta 39$ have been found in CSF of $\mathrm{AD}$ subjects. In $\mathrm{AD}$ patients, an increase in $\mathrm{A} \beta 38$ levels, accompanied with a decrease in $A \beta 42$ levels were also observed $[79,80]$. Thus, the $\mathrm{A} \beta 42 / \mathrm{A} \beta 38$ ratio might prove useful for more precise diagnosis of $\operatorname{AD}[79,80]$. Immunoprecipitation techniques and mass spectrometry have identified a number of short truncated $A \beta$ isoforms, such as $A \beta 14, A \beta 15$, and $A \beta 16$ in the CSF of AD patients. These forms have been reported to be produced through a novel pathway of APP processing involving the $\beta$ and $\alpha$ secretase actions [81]. In the $\mathrm{AD}$ subjects, elevated $\mathrm{A} \beta 16$ levels, accompanied with a decrease in $A \beta 42$ levels were reported in CSF [82].

5.2. CSF-Tau as a Biomarker. The protein tau is an intracellular protein, which maintains the stability of microtubules in neurons. In normal individual, only low concentration of tau is present in CSF. The function of tau is tightly regulated by a number of post-translational modifications including phosphorylation at serine and threonine residues. The precise form of tau in CSF and the mechanism for leakage of intracellular tau into CSF is not clearly understood. Despite intense research, the amyloid and tau pathologies remain unclear. Several experimental studies have suggested that hyperphosphorylation and NFT formation is the downstream phenomenon of AD pathologies [83]. However, it is also noteworthy that loss of function of tau due to hyperphosphorylation and subsequent detachment of tau from microtubule could lead to the increased cytoskeleton flexibility and loss of axonal integrity in the brain (Figure 1) [84]. In $\mathrm{AD}$, tau becomes hyperphosphorylated and gets dissociated from microtubule and subsequently polymerized into insoluble paired helical filaments (PHF) [84]. PHF eventually contributes to the formation of neurofibrillary tangles $[85,86]$. NFT formation and neuronal degradation is an essential part of AD pathology (Figure 1). Upon significant disruption of neuronal architecture, tau protein could be released into CSF [60]. Therefore, increased levels of tau and hyperphosphorylated tau in CSF can correlate with the onset of neurodegeneration in AD. The total tau ( $\mathrm{t}$-tau) concentration in CSF has been investigated by ELISA analysis using monoclonal antibodies against all tau isoforms. Several studies have suggested that t-tau concentration in CSF of $\mathrm{AD}$ patients is higher than control $[60,87]$. Although the CSF $t$-tau is very sensitive biomarker for detecting $\mathrm{AD}$, it has limited ability to discriminate $\mathrm{AD}$ from other major forms of dementia as t-tau also increased in CSF of others form of dementia including vascular dementia (VAD) and frontotemporal dementia (FTD) [60]. Several studies also used the p-tau in CSF as potential biomarkers since it is the major component of NFT. CSF concentrations of ptau in $\mathrm{AD}$ have been examined using ELISAs based on monoclonal antibodies that can detect its various epitopes of p-tau, namely, (Thr181 + Thr231), (Thr231 + Ser235), Ser199, Thr231, (Ser396 + Ser404), and Thr181 [41, 88, 89]. ELISA study using all antibodies has showed increased CSF concentration of p-tau in $\mathrm{AD}$ patients. Moreover, the ability of increased p-tau assays to discriminate $\mathrm{AD}$ from normal aging and other dementia is more sensitive and specific than that of CSF concentrations of $\mathrm{t}$-tau and A $\beta 42[60,90,91]$. The experimental evidences of high CSF concentrations of p-tau in only $\mathrm{AD}$ patients have suggested that $\mathrm{p}$-tau is not a simple marker of axonal damage and neuronal degeneration, as t-tau, but it is more closely related to $\mathrm{AD}$ pathology and the formation of NFT.

5.3. Combined $A \beta$ and Tau in CSF as Biomarkers. It has been suggested that combinations of CSF markers could more successfully discriminate $\mathrm{AD}$ from control or other forms of dementia than an individual marker. There are several studies where the diagnostic performance of the combination of CSF $t$-tau and $A \beta 42$ is analyzed. The evidences have suggested that high CSF concentration of t-tau and low concentrations of $\mathrm{A} \beta 42$ could detect $\mathrm{AD}$ with high diagnostic sensitivity and specificity [61]. The other combinations of CSF biomarkers have also been evaluated, which suggested that the high CSF $\mathrm{p}$-tau/A $\beta 42$ ratio possesses higher sensitivity and specificity [18] for differentiating $\mathrm{AD}$ from normal controls and from subjects with other non-AD dementia than that of the CSF t-tau, $\mathrm{p}$-tau, $\mathrm{A} \beta 42$, and ratio of $\mathrm{t}-\mathrm{tau} / \mathrm{A} \beta 42$. It is also suggested that the combination of tau and $A \beta 42$ has more diagnostic potential in terms of sensitivity and specificity in MCI patients to develop future $\mathrm{AD}[92]$.

5.4. Oligomers of $A \beta$ in CSF: Promising Biomarkers for Early Diagnosis in $A D$. Recent studies have suggested that oligomeric $A \beta s$ are the most neurotoxic species in AD. Substantial in vivo and in vitro evidence supports this hypothesis [93-97]. Several in vitro neurotoxicity studies have shown that $\mathrm{A} \beta$ oligomers are potent neurotoxins [98-104], and the toxicity of some oligomers is higher than that of the corresponding amyloid fibrils [105]. The evidences, which support the fact that $A \beta$ oligomers could be targeted for drug and biomarker discovery include (1) soluble oligomers could inhibit hippocampal long-term potentiation (LTP) [95, 98, $100,103,104,106,107]$ and disrupt cognitive function [108] in vivo; (2) compounds that bind and disrupt the formation of oligomers have been shown to block the neurotoxicity of $A \beta[108,109]$; (3) drugs that reduce the amyloid plaque burden without disruption of oligomers have little effect on recovery of neurological function [110]. Many oligomers such as $A \beta$-derived diffusible ligand (ADDL)-like $A \beta 42$ oligomers [111], $90 \mathrm{kDa} A \beta 42$ oligomer $[112,113], 56 \mathrm{kDa}$ oligomer of " $\mathrm{A} \beta * 56$ [114], and $\mathrm{A} \beta$ trimers [115] have shown high in vivo toxicity, providing a compelling reason for $\mathrm{A} \beta$ oligomers to be used as potential AD biomarkers especially for early diagnosis in AD. In addition, elevated levels of 
$\mathrm{A} \beta$ oligomers were detected in $\mathrm{AD}$ patients and transgenic mice compared to control [116-118]. The elevated level of oligomers could also appear in CSF but with lower concentration. Therefore, highly sensitive techniques are required for oligomer detection in CSF. The study using fluorescence correlation spectroscopy suggested the presence of $\mathrm{A} \beta$ oligomers in CSF of $\mathrm{AD}$ patients, compared to healthy control [119]. Recently, ultrasensitive, nanoparticlebased, protein detection assay (bio-barcode) showed that the ADDLs concentrations in CSF of $\mathrm{AD}$ patients were consistently higher than the nondemented age-matched control [120]. In this study, ADDLs specific antibodies coupled to DNA-tagged nanoparticles were used to capture the oligomers from the CSF of patients with AD. Although the number of $\mathrm{AD}$ patients and controls studied was low, the findings were very promising. Although $\mathrm{A} \beta$ oligomers are attractive biomarker candidates, several limitations exist to use these species. The concentration of these $A \beta$ oligomers in CSF is very low in comparison with $A \beta$ monomers. Again, the detection of individual $A \beta$ oligomers is difficult since oligomers are metastable and therefore one form of oligomers could transform to another form immediately. Assay sensitivity must reach very high level if one can detect total heterogeneous population of $A \beta$ oligomers in CSF. The monoclonal antibodies specific for only $\mathrm{A} \beta$ oligomers could be difficult to develop. Recently, an antibody against $\mathrm{A} \beta$ oligomers was developed, which can detect all $\mathrm{A} \beta$ oligomers, including oligomers from other amyloidogenic protein [117]. However, using these oligomers specific antibody to diagnose of $\mathrm{AD}$ is difficult since it cannot differentiate $\mathrm{AD}$ from other neurodegenerative diseases. New analytical methods and novel oligomers-specific antibody must be developed to detect oligomers in CSF of AD patients, which would have ultimate ability to detect early onset of $\mathrm{AD}$.

5.5. Neuronal Biomarkers in CSF. Besides tau and $\mathrm{A} \beta$, neuronal and synaptic proteins could also be used as CSF biomarkers in AD. For example, Visinin-like protein 1 (VLP1), a calcium sensor protein was shown to be significantly increased in the CSF of AD subjects compared to controls. It is believed to seep out from dented neurons [121]. The sensitivity and specificity of CSF VLP-1 is comparable to CSF t-tau, $p$-tau, and $A \beta 42$. Combined analysis of $\mathrm{A} \beta 42$, p-tau, and VLP-1 has been reported to raise the diagnostic precision of AD. VLP-1 biomarker might also prove useful in indicating the degree of dementia [121]. The neurofilaments, which are structural component of axons, could also be used as biomarkers for discriminating $\mathrm{AD}$ patients from other forms of dementia, as their expression levels are high in VAD and FTD [122], while normal levels are found in most $\mathrm{AD}$ patients. Another synaptic protein called growth-associated protein (GAP-43) is found in higher levels in CSF of AD than that of controls, and FTD [123]. Furthermore, it has been shown that CSF GAP43 and t-tau were increased in AD and correlated positively [123], suggesting both biomarkers are reflecting axonal and synaptic degeneration.
5.6. Oxidative Stress Marker in CSF. Besides the formation of amyloid plaque and NFT, AD is also frequently characterized by reactive oxygen species (ROS)-mediated neuronal damage. The oxidative damage in the brain mainly involves lipid peroxidation [124]. Polyunsaturated fatty acids are susceptible to oxidation by reactive oxygen species. Isoprostanes are lipid oxidation products generated due to the reaction between fatty acids and ROS. Therefore, isoprostanes could be used as valuable AD biomarkers. Several studies have suggested that F2-isoprostanes, a group of isoprostanes, are increased in CSF of AD patients compared to healthy control or patients with other dementia $[125,126]$. CSFF2-isoprostanes have also been shown to be increased in patients with $\mathrm{MCI}$ and asymptomatic carriers of familial $\mathrm{AD}$ mutations. A combined analysis of CSF-A $\beta 42$, tau, and F2isoprostanes, was able to diagnose $\mathrm{AD}$ with a sensitivity of $84 \%$ and specificity of $89 \%$ [127].

5.7. Inflammatory Biomarkers in CSF. AD pathology involves release of inflammatory mediators. The differential occurrence of several proteins due to inflammatory process in $\mathrm{AD}$ might be used as biomarker. These proteins can be detected using ELISA, as well as proteomics approaches. One of the most studied inflammatory biomarkers is $\alpha 1$-antichymotrypsin (A1ACT), which is observed either increased [45, 128] or unchanged [129] in CSF samples of $\mathrm{AD}$ patients. However, the contradictory results suggest that more studies must be conducted to raise the possibility of A1ACT to be regarded as an effective biomarker. The study of cytokines, which are produced during inflammation processes in $\mathrm{AD}$, also gave inconsistent results. For example, CSF interleukin-6 (IL-6) levels have been reported to be increased [130-132], decreased [133], or unchanged [134-136] in AD. Studies of IL-6 receptor, Gp130, and tumor necrosis factor (TNF- $\alpha$ ) also produced conflicting results [137]. The genetic background, environmental factors, and usage of anti-inflammatory drugs might produce substantial variation in cytokine levels in an individual [138]. This could be the reason for such uncertain results.

\section{CSF Biomarkers: A Potential Hope for AD Diagnosis}

As discussed in the preceding sections, most biomarker research in $\mathrm{AD}$ is based on either brain imaging or is fluid-based. Although imaging techniques are definitive tests for detecting amyloid plaques and atrophy using molecular probe, still antemortem diagnosis of $\mathrm{AD}$ and $\mathrm{MCI}$ are less successful. More sensitive chemical probes are required to be developed, which would bind oligomers or diffuse plaque. However, imaging techniques being very expensive and requiring more experience for handling the instruments precludes their day-to-day use for $\mathrm{AD}$ diagnosis. In fluid biomarker research, CSF has been proved to be a supreme source for biomarkers for several reasons. CSF is in close proximity to the brain, and therefore biochemical changes in the brain affect the composition of biomarkers in CSF. Since 
$\mathrm{AD}$ pathology is restricted to the brain, CSF is an obvious source of biomarkers for AD. CSF is also a rich source of brain-specific proteins, and changes in these protein levels are observed in CSF with disease progression. CSF biomarkers are also very sensitive to the fine changes in brain that occur in the preclinical stages of the AD. Therefore, CSF is probably the most informative fluid sample available for preclinical as well as symptomatic $\mathrm{AD}$ diagnosis. The diagnostic sensitivity and specificity of CSF biomarkers in differentiating $\mathrm{AD}$ from healthy controls, and from other forms of dementia is already achieved with satisfactory levels. Moreover, a combination of more than one biomarker in CSF, such as CSF p-tau, t-tau, and A 342 is considered to give higher diagnostic accuracy of $\mathrm{AD}$. It can identify $\mathrm{AD}$, prodromal $\mathrm{AD}$, and also can differentiate $\mathrm{AD}$ from other dementia with high sensitivity and specificity that is otherwise impossible to achieve.

Although CSF biomarkers have proved to be highly informative, sensitive, and specific for detection of clinical $\mathrm{AD}$ and early stage of $\mathrm{AD}$, their regular use in clinic is still limited. One of the major reasons against the vast applicability of CSF in AD diagnosis is lumbar puncture, an invasive method to collect the CSF sample. Other issues including inconsistency of data analysis of CSF sample due to sample collection, transportation, storage, and high expense of the test might limit the use of CSF for routine diagnosis. However, various strategies are available to resolve these issues. For example, the Clinical Neurochemistry Laboratory in Gothenburg, Sweden and Alzheimer's Association, have together started a quality control program, the objective of which is to standardize CSF biomarker measurements between both research and clinical laboratories [10]. This program would obviously enhance the diagnostic precision of CSF markers, thus enabling them to support a routine analysis for diagnosis of $\mathrm{AD}$.

\section{Future Direction}

According to the current clinical diagnostic criteria, $\mathrm{AD}$ diagnosis cannot be made until the patient has dementia, which is defined as cognitive symptoms severe enough to interfere with social or occupational activities [139]. This might hinder the preclinical diagnosis of $\mathrm{AD}$. The disease modifying drugs will be most effective and will have most therapeutic value if these are administered in the earliest stage of $\mathrm{AD}$, before amyloid plaques and NFT become prevalent. Since $\mathrm{AD}$ is a multifactorial neurodegenerative disorder both at clinical and neuropathological level, development of biomarkers with $100 \%$ efficiency in terms of sensitivity and specificity is difficult to achieve. Also, the effectiveness of the disease modifying drugs could vary from one subgroup to another subgroups, making the utility of biomarkers in clinical trial and drug discovery difficult. Combined analysis of CSF biomarkers represents more suitable diagnostic tool to detect $\mathrm{AD}$ patients or detect individuals with MCI. Moreover, sensitive assays should be developed to detect amyloid oligomers in CSF and in the brain. This would raise the possibility for the diagnosis of early onset of AD.

\section{Abbreviations}

$\mathrm{A} \beta: \quad$ Amyloid $\beta$ protein

ADDL: $\mathrm{A} \beta$-Derived diffusible ligand

APP: Amyloid precursor protein

BACE: $\beta$-site APP-cleaving enzyme

BBB: Blood brain barrier

CT: Computerized tomography

DLB: Dementia with Lewy bodies

FTD: Frontotemporal dementia

MCI: Mild cognitive impairment

MRI: Magnetic resonance imaging

NFT: Neurofibrillary tangles

PET: Positron emission tomography

PIB: $\quad$ Pittsburgh compound B

p-tau: Phosphorylated-tau

VAD: Vascular dementia.

\section{Acknowledgments}

The authors thank Soumen Maji for the cartoon drawing in Figure 1, Ashwani Kumar, and Dr. Sreenivas Chavali for their valuable suggestions during manuscript preparation. We would also like to thank CSIR, India (Grant no. 10CSIR001) for financial support.

\section{References}

[1] L. E. Hebert, P. A. Scherr, J. L. Bienias, D. A. Bennett, and D. A. Evans, "Alzheimer disease in the US population: prevalence estimates using the 2000 census," Archives of Neurology, vol. 60, no. 8, pp. 1119-1122, 2003.

[2] R. Brookmeyer, E. Johnson, K. Ziegler-Graham, and H. M. Arrighi, "Forecasting the global burden of Alzheimer's disease," Alzheimer's and Dementia, vol. 3, no. 3, pp. 186-191, 2007.

[3] D. J. Selkoe, "Cell biology of protein misfolding: the examples of Alzheimer's and Parkinson's diseases," Nature Cell Biology, vol. 6, no. 11, pp. 1054-1061, 2004.

[4] N.D. Lazo, S. K. Maji, E. A. Fradinger, et al., "The amyloid beta protein," in Amyloid Protein-The Beta Sheet Conformation and Disease, J. D. Sipe, Ed., pp. 385-491, Wiley-VCH Publishers, Weinheim, Germany, 2005.

[5] I. Grundke-Iqbal, K. Iqbal, and Y.-C. Tung, "Abnormal phosphorylation of the microtubule-associated protein $\tau$ (tau) in Alzheimer cytoskeletal pathology," Proceedings of the National Academy of Sciences of the United States of America, vol. 83, no. 13, pp. 44913-4917, 1986.

[6] I. Grundke-Iqbal, K. Iqbal, and M. Quinlan, "Microtubuleassociated protein tau. A component of Alzheimer paired helical filaments," The Journal of Biological Chemistry, vol. 261, no. 13, pp. 6084-6089, 1986.

[7] J. C. Morris, "The challenge of characterizing normal brain aging in relation to Alzheimer's disease," Neurobiology of Aging, vol. 18, no. 4, pp. 388-389, 1997.

[8] J. C. Morris and J. L. Price, "Pathologic correlates of nondemented aging, mild cognitive impairment, and earlystage Alzheimer's disease," Journal of Molecular Neuroscience, vol. 17, no. 2, pp. 101-118, 2001. 
[9] R. J. Perrin, A. M. Fagan, and D. M. Holtzman, "Multimodal techniques for diagnosis and prognosis of Alzheimer's disease," Nature, vol. 461, no. 7266, pp. 916-922, 2009.

[10] K. Blennow, H. Hampel, M. Weiner, and H. Zetterberg, "Cerebrospinal fluid and plasma biomarkers in Alzheimer disease," Nature Reviews Neurology, vol. 6, no. 3, pp. 131-144, 2010.

[11] C. M. Clark, C. Davatzikos, and A. Borthakur et al., "Biomarkers for early detection of Alzheimer pathology," NeuroSignals, vol. 16, no. 1, pp. 11-18, 2007.

[12] R. J. Killiany, T. Gomez-Isla, and M. Moss et al., "Use of structural magnetic resonance imaging to predict who will get Alzheimers disease," Annals of Neurology, vol. 47, no. 4, pp. 430-439, 2000.

[13] C. J. A. Moulin, M. Laine, and J. O. Rinne et al., "Brain function during multi-trial learning in mild cognitive impairment: a PET activation study," Brain Research, vol. 1136, no. 1, pp. 132-141, 2007.

[14] C. A. Mathis, Y. Wang, D. P. Holt, G.-F. Huang, M. L. Debnath, and W. E. Klunk, "Synthesis and evaluation of 11C-labeled 6-substituted 2-arylbenzothiazoles as amyloid imaging agents," Journal of Medicinal Chemistry, vol. 46, no. 13, pp. 2740-2754, 2003.

[15] A. Hye, S. Lynham, and M. Thambisetty et al., "Proteomebased plasma biomarkers for Alzheimer's disease," Brain, vol. 129, no. 11, pp. 3042-3050, 2006.

[16] Y.-M. Kuo, T. A. Kokjohn, and W. Kalback et al., "Amyloid$\beta$ peptides interact with plasma proteins and erythrocytes: implications for their quantitation in plasma," Biochemical and Biophysical Research Communications, vol. 268, no. 3, pp. 750-756, 2000.

[17] H. Fukumoto, M. Tennis, J. J. Locascio, B. T. Hyman, J. H. Growdon, and M. C. Irizarry, "Age but not diagnosis is the main predictor of plasma amyloid $\beta$-protein levels," Archives of Neurology, vol. 60, no. 7, pp. 958-964, 2003.

[18] A. Maddalena, A. Papassotiropoulos, and B. MüllerTillmanns et al., "Biochemical diagnosis of Alzheimer disease by measuring the cerebrospinal fluid ratio of phosphorylated tau protein to $\beta$-amyloid peptide42," Archives of Neurology, vol. 60, no. 9, pp. 1202-1206, 2003.

[19] C. D. Aluise, R. A. Sowell, and D. A. Butterfield, "Peptides and proteins in plasma and cerebrospinal fluid as biomarkers for the prediction, diagnosis, and monitoring of therapeutic efficacy of Alzheimer's disease," Biochimica et Biophysica Acta, vol. 1782, no. 10, pp. 549-558, 2008.

[20] K. Kantarci and C. R. Jack Jr., "Neuroimaging in Alzheimer disease: an evidence-based review," Neuroimaging Clinics of North America, vol. 13, no. 2, pp. 197-209, 2003.

[21] L. J. Thal, K. Kantarci, and E. M. Reiman et al., "The role of biomarkers in clinical trials for Alzheimer disease," Alzheimer Disease and Associated Disorders, vol. 20, no. 1, pp. 6-15, 2006.

[22] M. E. Raichle and M. A. Mintun, "Brain work and brain imaging," Annual Review of Neuroscience, vol. 29, pp. 449476, 2006.

[23] G. B. Frisoni, "Structural imaging in the clinical diagnosis of Alzheimer's disease: problems and tools," Journal of Neurology Neurosurgery and Psychiatry, vol. 70, no. 6, pp. 711-718, 2001.

[24] P. Scheltens, N. Fox, F. Barkhof, and C. De Carli, "Structural magnetic resonance imaging in the practical assessment of dementia: beyond exclusion," Lancet Neurology, vol. 1, no. 1, pp. 13-21, 2002.
[25] J. Barnes, J. L. Whitwell, C. Frost, K. A. Josephs, M. Rossor, and N. C. Fox, "Measurements of the amygdala and hippocampus in pathologically confirmed Alzheimer disease and frontotemporal lobar degeneration," Archives of Neurology, vol. 63, no. 10, pp. 1434-1439, 2006.

[26] J. Barnes, A. K. Godbolt, and C. Frost et al., "Atrophy rates of the cingulate gyrus and hippocampus in AD and FTLD," Neurobiology of Aging, vol. 28, no. 1, pp. 20-28, 2007.

[27] J. L. Whitwell and C. R. Jack Jr., "Comparisons between Alzheimer disease, frontotemporal lobar degeneration, and normal aging with brain mapping," Topics in Magnetic Resonance Imaging, vol. 16, no. 6, pp. 409-425, 2005.

[28] J. T. Becker, M. A. Mintun, K. Aleva, M. B. Wiseman, T. Nichols, and S. T. DeKosky, "Compensatory reallocation of brain resources supporting verbal episodic memory in Alzheimer's disease," Neurology, vol. 46, no. 3, pp. 692-700, 1996.

[29] C. L. Grady, M. L. Furey, P. Pietrini, B. Horwitz, and S. I. Rapoport, "Altered brain functional connectivity and impaired short-term memory in Alzheimer's disease," Brain, vol. 124, no. 4, pp. 739-756, 2001.

[30] J. L. Woodard, S. T. Grafton, J. R. Votaw, R. C. Green, M. E. Dobraski, and J. M. Hoffman, "Compensatory recruitment of neural resources during overt rehearsal of word lists in Alzheimer's disease," Neuropsychology, vol. 12, no. 4, pp. 491504, 1998.

[31] M. A. Mintun, G. N. Larossa, and Y. I. Sheline et al., "[11C]PIB in a nondemented population: potential antecedent marker of Alzheimer disease," Neurology, vol. 67, no. 3, pp. 446-452, 2006.

[32] W. E. Klunk, H. Engler, and A. Nordberg et al., "Imaging brain amyloid in alzheimer's disease with pittsburgh compound-B," Annals of Neurology, vol. 55, no. 3, pp. 306$319,2004$.

[33] A. M. Fagan, M. A. Mintun, R. H. Mach, et al., "Inverse relation between in vivo amyloid imaging load and cerebrospinal fluid Abeta42 in humans," Annals of Neurology, vol. 59, no. 3, pp. 512-519, 2006.

[34] A. M. Fagan, C. M. Roe, C. Xiong, M. A. Mintun, J. C. Morris, and D. M. Holtzman, "Cerebrospinal fluid tau/ $\beta$-amyloid 42 ratio as a prediction of cognitive decline in nondemented older adults," Archives of Neurology, vol. 64, no. 3, pp. 343$349,2007$.

[35] A. Forsberg, H. Engler, and O. Almkvist et al., "PET imaging of amyloid deposition in patients with mild cognitive impairment," Neurobiology of Aging, vol. 29, no. 10, pp. 14561465, 2008.

[36] R. Motter, C. Vigopelfrey, D. Kholodenko, et al., "Reduction of beta-amyloid peptide(42), in the cerebrospinal fluid of patients with Alzheimers disease," Annals of Neurology, vol. 38, no. 4, pp. 643-648, 1995.

[37] S. C. Samuels, J. M. Silverman, and D. B. Marin et al., "CSF beta-amyloid, cognition, and APOE genotype in Alzheimer's disease," Neurology, vol. 52, no. 3, pp. 547-551, 1999.

[38] P. Edison, H. A. Archer, and A. Gerhard et al., "Microglia, amyloid, and cognition in Alzheimer's disease: an [11C](R)PK11195-PET and [11C]PIB-PET study," Neurobiology of Disease, vol. 32, no. 3, pp. 412-419, 2008.

[39] S. Nakamura, T. Kawamata, I. Akiguchi, M. Kameyama, N. Nakamura, and H. Kimura, "Expression of monoamine oxidase B activity in astrocytes of senile plaques," Acta Neuropathologica, vol. 80, no. 4, pp. 419-425, 1990. 
[40] J. Hirvonen, M. Kailajärvi, and T. Haltia et al., "Assessment of MAO-B occupancy in the brain with PET and 11 C-Ldeprenyl-D 2: a dose-finding study with a novel MAO-B inhibitor, EVT 301," Clinical Pharmacology and Therapeutics, vol. 85, no. 5, pp. 506-512, 2009.

[41] K. Blennow and H. Hampel, "CSF markers for incipient Alzheimer's disease," Lancet Neurology, vol. 2, no. 10, pp. 605-613, 2003.

[42] J. Bauer, S. Strauss, and U. Schreiter-Gasser et al., "Interleukin-6 and $\alpha$-2-macroglobulin indicate an acutephase state in Alzheimer's disease cortices," FEBS Letters, vol. 285, no. 1, pp. 111-114, 1991.

[43] R. Strohmeyer, M. Ramirez, G. J. Cole, K. Mueller, and J. Rogers, "Association of factor $\mathrm{H}$ of the alternative pathway of complement with agrin and complement receptor 3 in the Alzheimer's disease brain," Journal of Neuroimmunology, vol. 131, no. 1-2, pp. 135-146, 2002.

[44] O. C. Maes, S. Kravitz, and Y. Mawal et al., "Characterization of $\alpha 1$-antitrypsin as a heme oxygenase- 1 suppressor in Alzheimer plasma," Neurobiology of Disease, vol. 24, no. 1, pp. 89-100, 2006.

[45] E. Matsubara, S. Hirai, and M. Amari et al., " $\alpha 1$ antichymotrypsin as a possible biochemical marker for Alzheimer-type dementia," Annals of Neurology, vol. 28, no. 4, pp. 561-567, 1990.

[46] J. Liebermann, L. Schleissner, K. H. Tachiki, and A. S. Kling, "Serum $\alpha 1$-antichymotrypsin level as a marker for Alzheimer-type dementia," Neurobiology of Aging, vol. 16, no. 5, pp. 747-753, 1995.

[47] A. Merched, Y. Xia, S. Visvikis, J. M. Serot, and G. Siest, "Decreased high-density lipoprotein cholesterol and serum apolipoprotein AI concentrations are highly correlated with the severity of Alzheimer's disease," Neurobiology of Aging, vol. 21, no. 1, pp. 27-30, 2000.

[48] M. C. Irizarry, "Biomarkers of Alzheimer Disease in Plasma," NeuroRx, vol. 1, no. 2, pp. 226-234, 2004.

[49] N. R. Graff-Radford, J. E. Crook, and J. Lucas et al., "Association of low plasma $\mathrm{A} \beta 42 / \mathrm{A} \beta 40$ ratios with increased imminent risk for mild cognitive impairment and Alzheimer disease," Archives of Neurology, vol. 64, no. 3, pp. 354-362, 2007.

[50] S. Ray, M. Britschgi, and C. Herbert et al., "Classification and prediction of clinical Alzheimer's diagnosis based on plasma signaling proteins," Nature Medicine, vol. 13, no. 11, pp. 1359-1362, 2007.

[51] H. Ghanbari, K. Ghanbari, I. Beheshti, M. Munzar, A. Vasauskas, and P. Averback, "Biochemical assay for AD7CNTP in urine as an Alzheimer's disease marker," Journal of Clinical Laboratory Analysis, vol. 12, no. 5, pp. 285-288, 1998.

[52] S. Levy, M. McConville, G. A. Lazaro, and P. Averback, "Competitive ELISA studies of neural thread protein in urine in Alzheimer's disease," Journal of Clinical Laboratory Analysis, vol. 21, no. 1, pp. 24-33, 2007.

[53] S. M. de la Monte and J. R. Wands, "The AD7c-ntp neuronal thread protein biomarker for detecting Alzheimer's disease," Frontiers in Bioscience, vol. 7, pp. d989-996, 2002.

[54] D. Praticò, C. M. Clark, V. M.-Y. Lee, J. Q. Trojanowski, J. Rokach, and G. A. Fitzgerald, "Increased 8,12-iso-iPF(2 $\alpha)$-VI in Alzheimer's disease: correlation of a noninvasive index of lipid peroxidation with disease severity," Annals of Neurology, vol. 48 , no. 5, pp. 809-812, 2000.
[55] D. Praticò, C. M. Clark, F. Liun, V. Y.-M. Lee, and J. Q. Trojanowski, "Increase of brain oxidative stress in mild cognitive impairment: a possible predictor of Alzheimer disease," Archives of Neurology, vol. 59, no. 6, pp. 972-976, 2002.

[56] E. E. Tuppo, L. J. Forman, B. W. Spur, R. E. Chan-Ting, A. Chopra, and T. A. Cavalieri, "Sign of lipid peroxidation as measured in the urine of patients with probable Alzheimer's disease," Brain Research Bulletin, vol. 54, no. 5, pp. 565-568, 2001.

[57] K. C. Bohnstedt, B. Karlberg, L.-O. Wahlund, M. E. Jönhagen, H. Basun, and S. Schmidt, "Determination of isoprostanes in urine samples from Alzheimer patients using porous graphitic carbon liquid chromatography-tandem mass spectrometry," Journal of Chromatography B, vol. 796, no. 1, pp. 11-19, 2003.

[58] T. J. Montine, L. Shinobu, and K. S. Montine et al., "No difference in plasma or urinary F2-isoprostanes among patients with Huntington's disease or Alzheimer's disease and controls," Annals of Neurology, vol. 48, no. 6, p. 950, 2000.

[59] V. Thongboonkerd, "Practical points in urinary proteomics," Journal of Proteome Research, vol. 6, no. 10, pp. 3881-3890, 2007.

[60] P. Formichi, C. Battisti, E. Radi, and A. Federico, "Cerebrospinal fluid tau, $\mathrm{A} \beta$, and phosphorylated tau protein for the diagnosis of Alzheimer's disease," Journal of Cellular Physiology, vol. 208, no. 1, pp. 39-46, 2006.

[61] R. Craig-Schapiro, A. M. Fagan, and D. M. Holtzman, "Biomarkers of Alzheimer's disease," Neurobiology of Disease, vol. 35, no. 2, pp. 128-140, 2009.

[62] M. Citron, T. S. Diehl, G. Gordon, A. L. Biere, P. Seubert, and D. J. Selkoe, "Evidence that the 42- and 40-amino acid forms of amyloid $\beta$ protein are generated from the $\beta$-amyloid precursor protein by different protease activities," Proceedings of the National Academy of Sciences of the United States of America, vol. 93, no. 23, pp. 13170-13175, 1996.

[63] W. E. Van Nostrand, S. L. Wagner, and W. R. Shankle et al., "Decreased levels of soluble amyloid $\beta$-protein precursor in cerebrospinal fluid of live Alzheimer disease patients," Proceedings of the National Academy of Sciences of the United States of America, vol. 89, no. 7, pp. 2551-2555, 1992.

[64] A. E. Roher, J. D. Lowenson, and S. Clarke et al., " $\beta$-Amyloid(1-42) is a major component of cerebrovascular amyloid deposits: implications for the pathology of Alzheimer disease," Proceedings of the National Academy of Sciences of the United States of America, vol. 90, no. 22, pp. 10836-10840, 1993.

[65] L. Lannfelt, H. Basun, and C. Vigo-Pelfrey et al., "Amyloid $\beta$-peptide in cerebrospinal fluid in individuals with the Swedish Alzheimer amyloid precursor protein mutation," Neuroscience Letters, vol. 199, no. 3, pp. 203-206, 1995.

[66] N. Andreasen, C. Hesse, and P. Davidsson et al., "Cerebrospinal fluid $\beta$-amyloid(1-42) in Alzheimer disease: differences between early- and late-onset Alzheimer disease and stability during the course of disease," Archives of Neurology, vol. 56, no. 6, pp. 673-680, 1999.

[67] D. Galasko, L. Chang, and R. Motter et al., "High cerebrospinal fluid tau and low amyloid $\beta 42$ levels in the clinical diagnosis of Alzheimer disease and relation to apolipoprotein E genotype," Archives of Neurology, vol. 55, no. 7, pp. 937945, 1998.

[68] H. Hampel, S. J. Teipel, and T. Fuchsberger et al., "Value of CSF $\beta$-amyloid1-42 and tau as predictors of Alzheimer's 
disease in patients with mild cognitive impairment," Molecular Psychiatry, vol. 9, no. 7, pp. 705-710, 2004.

[69] P. Lewczuk, H. Esselmann, and M. Otto et al., "Neurochemical diagnosis of Alzheimer's dementia by CSF A $\beta 42$, A $\beta 42 / A \beta 40$ ratio and total tau," Neurobiology of Aging, vol. 25, no. 3, pp. 273-281, 2004.

[70] C. Mulder, S. N. M. Schoonenboom, and L.-O. Wahlund et al., "CSF markers related to pathogenetic mechanisms in Alzheimer's disease," Journal of Neural Transmission, vol. 109, no. 12, pp. 1491-1498, 2002.

[71] M. Jensen, J. Schröder, and M. Blomberg et al., "Cerebrospinal fluid A $\beta 42$ is increased early in sporadic Alzheimer's disease and declines with disease progression," Annals of Neurology, vol. 45, no. 4, pp. 504-511, 1999.

[72] J. G. Csernansky, J. P. Miller, D. McKeel, and J. C. Morris, "Relationships among cerebrospinal fluid biomarkers in dementia of the Alzheimer type," Alzheimer Disease and Associated Disorders, vol. 16, no. 3, pp. 144-149, 2002.

[73] R. B. DeMattos, K. R. Bales, and M. Parsadanian et al., "Plaque-associated disruption of CSF and plasma amyloid- $\beta$ $(\mathrm{A} \beta)$ equilibrium in a mouse model of Alzheimer's disease," Journal of Neurochemistry, vol. 81, no. 2, pp. 229-236, 2002.

[74] F. Hulstaert, K. Blennow, and A. Ivanoiu et al., "Improved discrimination of $\mathrm{AD}$ patients using $\beta$-amyloid (1-42) and tau levels in CSF," Neurology, vol. 52, no. 8, pp. 1555-1562, 1999.

[75] M. Riemenschneider, S. Wagenpfeil, and J. Diehl et al., "Tau and $\mathrm{A} \beta 42$ protein in CSF of patients with frontotemporal degeneration," Neurology, vol. 58, no. 11, pp. 1622-1628, 2002.

[76] M. Sjögren, L. Minthon, and P. Davidsson et al., "CSF levels of tau, $\beta$-amyloid1-42 and GAP-43 in frontotemporal dementia, other types of dementia and normal aging," Journal of Neural Transmission, vol. 107, no. 5, pp. 563-579, 2000.

[77] N. J. Cairns, M. D. Ikonomovic, T. Benzinger, et al., "Absence of Pittsburgh compound B detection of cerebral amyloid $\beta$ in a patient with clinical, cognitive, and cerebrospinal fluid markers of Alzheimer disease: a case report," Archives of Neurology, vol. 66, no. 12, pp. 1557-1562, 2009.

[78] O. Hansson, H. Zetterberg, and P. Buchhave et al., "Prediction of Alzheimer's disease using the CSF A $\beta 42 / \mathrm{A} \beta 40$ ratio in patients with mild cognitive impairment," Dementia and Geriatric Cognitive Disorders, vol. 23, no. 5, pp. 316-320, 2007.

[79] P. Lewczuk, H. Esselmann, and M. Meyer et al., "The amyloid- $\beta(\mathrm{A} \beta)$ peptide pattern in cerebrospinal fluid in Alzheimer's disease: evidence of a novel carboxyterminally elongated A $\beta$ peptide," Rapid Communications in Mass Spectrometry, vol. 17, no. 12, pp. 1291-1296, 2003.

[80] N. S. Schoonenboom, C. Mulder, and G. J. Van Kamp et al., "Amyloid $\beta 38,40$, and 42 species in cerebrospinal fluid: more of the same?" Annals of Neurology, vol. 58, no. 1, pp. 139-142, 2005.

[81] E. Portelius, E. Price, and G. Brinkmalm et al., "A novel pathway for amyloid precursor protein processing," Neurobiology of Aging. In press.

[82] E. Portelius, H. Zetterberg, and U. Andreasson et al., "An Alzheimer's disease-specific $\beta$-amyloid fragment signature in cerebrospinal fluid," Neuroscience Letters, vol. 409, no. 3, pp. 215-219, 2006.
[83] J. Lewis, D. W. Dickson, and W.-L. Lin et al., "Enhanced neurofibrillary degeneration in transgenic mice expressing mutant tau and APP," Science, vol. 293, no. 5534, pp. 14871491, 2001.

[84] E.-M. Mandelkow and E. Mandelkow, “Tau in Alzheimer's disease," Trends in Cell Biology, vol. 8, no. 11, pp. 425-427, 1998.

[85] M. Goedert, "Tau protein and the neurofibrillary pathology of Alzheimer's disease," Trends in Neurosciences, vol. 16, no. 11, pp. 460-465, 1993.

[86] K. Iqbal, A. D. C. Alonso, and C.-X. Gong et al., "Mechanisms of neurofibrillary degeneration and the formation of neurofibrillary tangles," Journal of Neural Transmission, Supplement, no. 53, pp. 169-180, 1998.

[87] M. Vandermeeren, M. Mercken, and E. Vanmechelen et al., "Detection of $\tau$ proteins in normal and Alzheimer's disease cerebrospinal fluid with a sensitive sandwich enzyme-linked immunosorbent assay," Journal of Neurochemistry, vol. 61, no. 5, pp. 1828-1834, 1993.

[88] Y.-I. Morikawa, H. Arai, and S. Matsushita et al., "Cerebrospinal fluid tau protein levels in demented and nondemented alcoholics," Alcoholism: Clinical and Experimental Research, vol. 23, no. 4, pp. 575-577, 1999.

[89] Y. Y. Hu, S. S. He, and X. Wang et al., "Levels of nonphosphorylated and phosphorylated tau in cerebrospinal fluid of Alzheimer's disease patients: an ultrasensitive bienzyme-substrate-recycle enzyme-linked immunosorbent assay," American Journal of Pathology, vol. 160, no. 4, pp. 1269-1278, 2002.

[90] H. Hampel, K. Buerger, and R. Zinkowski et al., "Measurement of phosphorylated tau epitopes in the differential diagnosis of Alzheimer disease: a comparative cerebrospinal fluid study," Archives of General Psychiatry, vol. 61, no. 1, pp. 95-102, 2004.

[91] K. Koopman, N. Le Bastard, J.-J. Martin, G. Nagels, P. P. De Deyn, and S. Engelborghs, "Improved discrimination of autopsy-confirmed Alzheimer's disease (AD) from non-AD dementias using CSF P-tau181P," Neurochemistry International, vol. 55, no. 4, pp. 214-218, 2009.

[92] G. Li, I. Sokal, and J. F. Quinn et al., "CSF tau/A $\beta 42$ ratio for increased risk of mild cognitive impairment: a follow-up study," Neurology, vol. 69, no. 7, pp. 631-639, 2007.

[93] S. K. Maji, R. R. Ogorzalek Loo, and M. Inayathullah et al., "Amino acid position-specific contributions to amyloid $\beta$ protein oligomerization," The Journal of Biological Chemistry, vol. 284, no. 35, pp. 23580-23591, 2009.

[94] M. D. Kirkitadze, G. Bitan, and D. B. Teplow, "Paradigm shifts in Alzheimer's disease and other neurodegenerative disorders: the emerging role of oligomeric assemblies," Journal of Neuroscience Research, vol. 69, no. 5, pp. 567-577, 2002.

[95] W. L. Klein, W. B. Stine Jr., and D. B. Teplow, "Small assemblies of unmodified amyloid $\beta$-protein are the proximate neurotoxin in Alzheimer's disease," Neurobiology of Aging, vol. 25, no. 5, pp. 569-580, 2004.

[96] D. M. Walsh and D. J. Selkoe, "A $\beta$ oligomers-a decade of discovery," Journal of Neurochemistry, vol. 101, no. 5, pp. 1172-1184, 2007.

[97] J. Hardy and D. J. Selkoe, "The amyloid hypothesis of Alzheimer's disease: progress and problems on the road to therapeutics," Science, vol. 297, no. 5580, pp. 353-356, 2002. 
[98] D. M. Walsh, I. Klyubin, and J. V. Fadeeva et al., "Naturally secreted oligomers of amyloid $\beta$ protein potently inhibit hippocampal long-term potentiation in vivo," Nature, vol. 416, no. 6880, pp. 535-539, 2002.

[99] T. Oda, P. Wals, and H. H. Osterburg et al., "Clusterin (apoJ) alters the aggregation of amyloid $\beta$-peptide $\left(\mathrm{A} \beta_{1-42}\right)$ and forms slowly sedimenting $\mathrm{A} \beta$ complexes that cause oxidative stress," Experimental Neurology, vol. 136, no. 1, pp. 22-31, 1995.

[100] M. P. Lambert, A. K. Barlow, and B. A. Chromy et al., "Diffusible, nonfibrillar ligands derived from $\mathrm{A} \beta_{1-42}$ are potent central nervous system neurotoxins," Proceedings of the National Academy of Sciences of the United States of America, vol. 95, no. 11, pp. 6448-6453, 1998.

[101] D. M. Walsh, D. M. Hartley, and Y. Kusumoto et al., "Amyloid $\beta$-protein fibrillogenesis. Structure and biological activity of protofibrillar intermediates," The Journal of Biological Chemistry, vol. 274, no. 36, pp. 25945-25952, 1999.

[102] D. M. Hartley, D. M. Walsh, and C. P. Ye et al., "Protofibrillar intermediates of amyloid $\beta$-protein induce acute electrophysiological changes and progressive neurotoxicity in cortical neurons," Journal of Neuroscience, vol. 19, no. 20, pp. 88768884, 1999.

[103] Q.-S. Chen, B. L. Kagan, Y. Hirakura, and C.-W. Xie, "Impairment of hippocampal long-term potentiation by Alzheimer amyloid $\beta$-peptides," Journal of Neuroscience Research, vol. 60 , no. 1 , pp. 65-72, 2000.

[104] J. Nalbantoglu, G. Tirado-Santiago, and A. Lahsaïni et al., "Impaired learning and LTP in mice expressing the carboxy terminus of the Alzheimer amyloid precursor protein," Nature, vol. 387, no. 6632, pp. 500-505, 1997.

[105] K. N. Dahlgren, A. M. Manelli, W. Blaine Stine Jr., L. K. Baker, G. A. Krafft, and M. J. Ladu, "Oligomeric and fibrillar species of amyloid- $\beta$ peptides differentially affect neuronal viability," The Journal of Biological Chemistry, vol. 277, no. 35, pp. 32046-32053, 2002.

[106] I. Klyubin, D. M. Walsh, and W. K. Cullen et al., "Soluble Arctic amyloid $\beta$ protein inhibits hippocampal long-term potentiation in vivo," European Journal of Neuroscience, vol. 19, no. 10, pp. 2839-2846, 2004.

[107] H.-W. Wang, J. F. Pasternak, and H. Kuo et al., "Soluble oligomers of $\beta$ amyloid (1-42) inhibit long-term potentiation but not long-term depression in rat dentate gyrus," Brain Research, vol. 924, no. 2, pp. 133-140, 2002.

[108] J. P. Cleary, D. M. Walsh, and J. J. Hofmeister et al., "Natural oligomers of the amyloid- $\beta$ protein specifically disrupt cognitive function," Nature Neuroscience, vol. 8, no. 1, pp. 79-84, 2005.

[109] F. G. De Felice, M. N. N. Vieira, M. N. L. Meirelles, L. A. Morozova-Roche, C. M. Dobson, and S. T. Ferreira, "Formation of amyloid aggregates from human lysozyme and its disease-associated variants using hydrostatic pressure," FASEB Journal, vol. 18, no. 10, pp. 1099-1101, 2004.

[110] E. Head, V. Pop, V. Vasilevko, et al., "A two-year study with fibrillar beta-amyloid (Abeta) immunization in aged canines: effects on cognitive function and brain Abeta," The Journal of Neuroscience, vol. 28, no. 14, pp. 3555-3566, 2008.

[111] J. A. White, A. M. Manelli, K. H. Holmberg, L. J. Van Eldik, and M. J. LaDu, "Differential effects of oligomeric and fibrillar amyloid- $\beta 1-42$ on astrocyte-mediated inflammation," Neurobiology of Disease, vol. 18, no. 3, pp. 459-465, 2005.

[112] A. Demuro, E. Mina, R. Kayed, S. C. Milton, I. Parker, and C. G. Glabe, "Calcium dysregulation and membrane disruption as a ubiquitous neurotoxic mechanism of soluble amyloid oligomers," The Journal of Biological Chemistry, vol. 280, no. 17, pp. 17294-17300, 2005.

[113] Y.H. Chong, Y. J. Shin, E.O. Lee, et al., "ERK1/2 activation mediates $\mathrm{A} \beta$ oligomer-induced neurotoxicity via caspase- 3 activation and Tau cleavage in rat organotypic hippocampal slice cultures," The Journal of Biological Chemistry, vol. 281, no. 29, pp. 20315-20325, 2006.

[114] S. Lesné, T. K. Ming, and L. Kotilinek et al., "A specific amyloid- $\beta$ protein assembly in the brain impairs memory," Nature, vol. 440, no. 7082, pp. 352-357, 2006.

[115] M. Townsend, G. M. Shankar, T. Mehta, D. M. Walsh, and D. J. Selkoe, "Effects of secreted oligomers of amyloid $\beta$-protein on hippocampal synaptic plasticity: a potent role for trimers," Journal of Physiology, vol. 572, no. 2, pp. 477-492, 2006.

[116] Y.-M. Kuo, M. R. Emmerling, and C. Vigo-Pelfrey et al., "Water-soluble $\mathrm{A} \beta(\mathrm{N}-40, \mathrm{~N}-42)$ oligomers in normal and Alzheimer disease brains," The Journal of Biological Chemistry, vol. 271, no. 8, pp. 4077-4081, 1996.

[117] R. Kayed, E. Head, and J. L. Thompson et al., "Common structure of soluble amyloid oligomers implies common mechanism of pathogenesis," Science, vol. 300, no. 5618, pp. 486-489, 2003.

[118] Y. Gong, L. Chang, and K. L. Viola et al., "Alzheimer's disease-affected brain: presence of oligomeric $A \beta$ ligands (ADDLs) suggests a molecular basis for reversible memory loss," Proceedings of the National Academy of Sciences of the United States of America, vol. 100, no. 18, pp. 10417-10422, 2003.

[119] M. Pitschke, R. Prior, M. Haupt, and D. Riesner, "Detection of single amyloid $\beta$-protein aggregates in the cerebrospinal fluid of Alzheirner's patients by fluorescence correlation spectroscopy," Nature Medicine, vol. 4, no. 7, pp. 832-834, 1998.

[120] D. G. Georganopoulou, L. Chang, and J.-M. Nam et al., "Nanoparticle-based detection in cerebral spinal fluid of a soluble pathogenic biomarker for Alzheimer's disease," Proceedings of the National Academy of Sciences of the United States of America, vol. 102, no. 7, pp. 2273-2276, 2005.

[121] J.-M. Lee, K. Blennow, and N. Andreasen et al., "The brain injury biomarker VLP-1 is increased in the cerebrospinal fluid of Alzheimer disease patients," Clinical Chemistry, vol. 54, no. 10, pp. 1617-1623, 2008.

[122] L. E. Rosengren, J.-E. Karlsson, M. Sjögren, K. Blennow, and A. Wallin, "Neurofilament protein levels in CSF are increased in dementia," Neurology, vol. 52, no. 5, pp. 1090-1093, 1999.

[123] M. Sjögren, P. Davidsson, and J. Gottfries et al., "The cerebrospinal fluid levels of tau, growth-associated protein43 and soluble amyloid precursor protein correlate in Alzheimer's disease, reflecting a common pathophysiological process," Dementia and Geriatric Cognitive Disorders, vol. 12, no. 4, pp. 257-264, 2001.

[124] D. Praticò, "Alzheimer's disease and oxygen radicals: new insights," Biochemical Pharmacology, vol. 63, no. 4, pp. 563$567,2002$.

[125] T. J. Montine, M. F. Beal, and M. E. Cudkowicz et al., "Increased CSF F2-isoprostane concentration in probable AD," Neurology, vol. 52, no. 3, pp. 562-565, 1999.

[126] D. Praticò, V. M.-Y. Lee, J. Q. Trojanowski, J. Rokach, and G. A. Fitzgerald, "Increased F2-isoprostanes in Alzheimer's disease: evidence for enhanced lipid peroxidation in vivo," FASEB Journal, vol. 12, no. 15, pp. 1777-1783, 1998.

[127] T. J. Montine, J. A. Kaye, K. S. Montine, et al., "Cerebrospinal fluid abeta42, tau, and f2-isoprostane concentrations in patients with Alzheimer disease, other dementias, and in 
age-matched controls," Archives of Pathology \& Laboratory Medicine, vol. 125, no. 4, pp. 510-512, 2001.

[128] Y. Harigaya, M. Shoji, T. Nakamura, E. Matsubara, K. Hosoda, and S. Hirai, "Alpha 1-antichymotrypsin level in cerebrospinal fluid is closely associated with late onset Alzheimer's disease," Internal Medicine, vol. 34, no. 6, pp. 481-484, 1995.

[129] T. Pirttila, P. D. Mehta, H. Frey, and H. M. Wisniewski, “ $\alpha 1$ Antichymotrypsin and IL-1 $\beta$ are not increased in CSF or serum in Alzheimer's disease," Neurobiology of Aging, vol. 15, no. 3, pp. 313-317, 1994.

[130] D. Blum-Degena, T. Müller, W. Kuhn, M. Gerlach, H. Przuntek, and P. Riederer, "Interleukin- $1 \beta$ and interleukin-6 are elevated in the cerebrospinal fluid of Alzheimer's and de novo Parkinson's disease patients," Neuroscience Letters, vol. 202, no. 1-2, pp. 17-20, 1995.

[131] J. P. Jia, R. Meng, Y. X. Sun, W. J. Sun, X. M. Ji, and L. F. Jia, "Cerebrospinal fluid tau, A $\beta 1-42$ and inflammatory cytokines in patients with Alzheimer's disease and vascular dementia," Neuroscience Letters, vol. 383, no. 1-2, pp. 12-16, 2005.

[132] M. Martínez, E. Fernández-Vivancos, A. Frank, M. De La Fuente, and A. Hernanz, "Increased cerebrospinal fluid Fas (Apo-1) levels in Alzheimer's disease: relationship with IL-6 concentrations," Brain Research, vol. 869, no. 1-2, pp. 216219, 2000.

[133] K. Yamada, K. Kono, and H. Umegaki et al., "Decreased interleukin-6 level in the cerebrospinal fluid of patients with Alzheimer-type dementia," Neuroscience Letters, vol. 186, no. 2-3, pp. 219-221, 1995.

[134] S. Engelborghs, M. De Brabander, and J. De Crée et al., "Unchanged levels of interleukins, neopterin, interferon- $\gamma$ and tumor necrosis factor- $\alpha$ in cerebrospinal fluid of patients with dementia of the Alzheimer type," Neurochemistry International, vol. 34, no. 6, pp. 523-530, 1999.

[135] P. März, K. Heese, and C. Hock et al., "Interleukin-6 (IL-6) and soluble forms of IL- 6 receptors are not altered in cerebrospinal fluid of Alzheimer's disease patients," Neuroscience Letters, vol. 239, no. 1, pp. 29-32, 1997.

[136] E. Tarkowski, K. Blennow, A. Wallin, and A. Tarkowski, "Intracerebral production of tumor necrosis factor- $\alpha$, a local neuroprotective agent, in Alzheimer disease and vascular dementia," Journal of Clinical Immunology, vol. 19, no. 4, pp. 223-230, 1999.

[137] C. E. Teunissen, J. de Vente, H. W. M. Steinbusch, and C. De Bruijn, "Biochemical markers related to Alzheimer's dementia in serum and cerebrospinal fluid," Neurobiology of Aging, vol. 23, no. 4, pp. 485-508, 2002.

[138] M. Flirski and T. Sobow, "Biochemical markers and risk factors of Alzheimer's disease," Current Alzheimer Research, vol. 2, no. 1, pp. 47-64, 2005.

[139] B. Dubois, H. H. Feldman, and C. Jacova et al., "Research criteria for the diagnosis of Alzheimer's disease: revising the NINCDS-ADRDA criteria," Lancet Neurology, vol. 6, no. 8, pp. 734-746, 2007. 


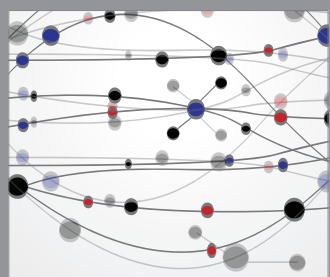

The Scientific World Journal
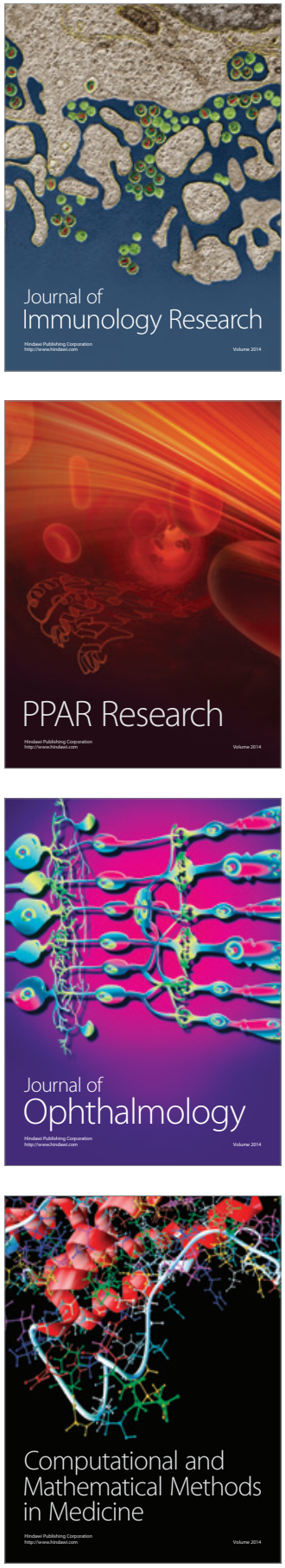

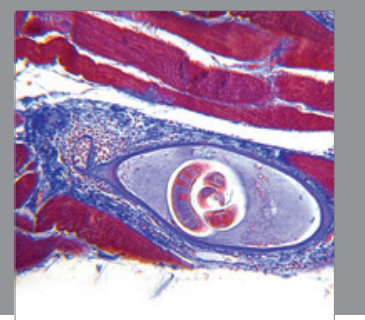

Gastroenterology

Research and Practice
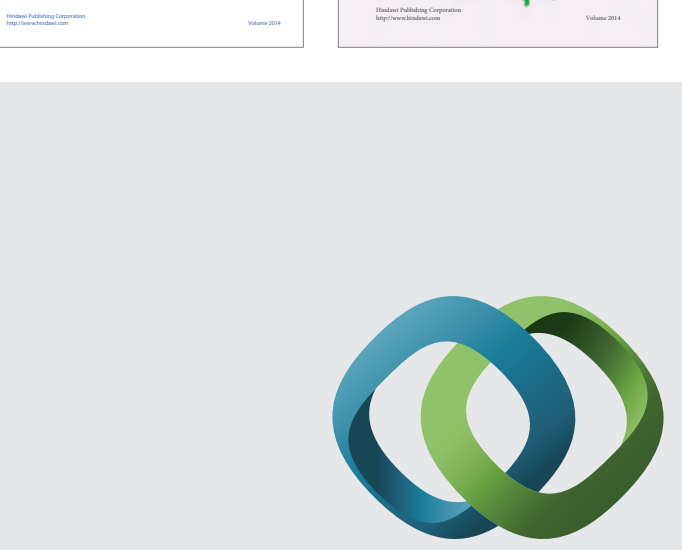

\section{Hindawi}

Submit your manuscripts at

http://www.hindawi.com
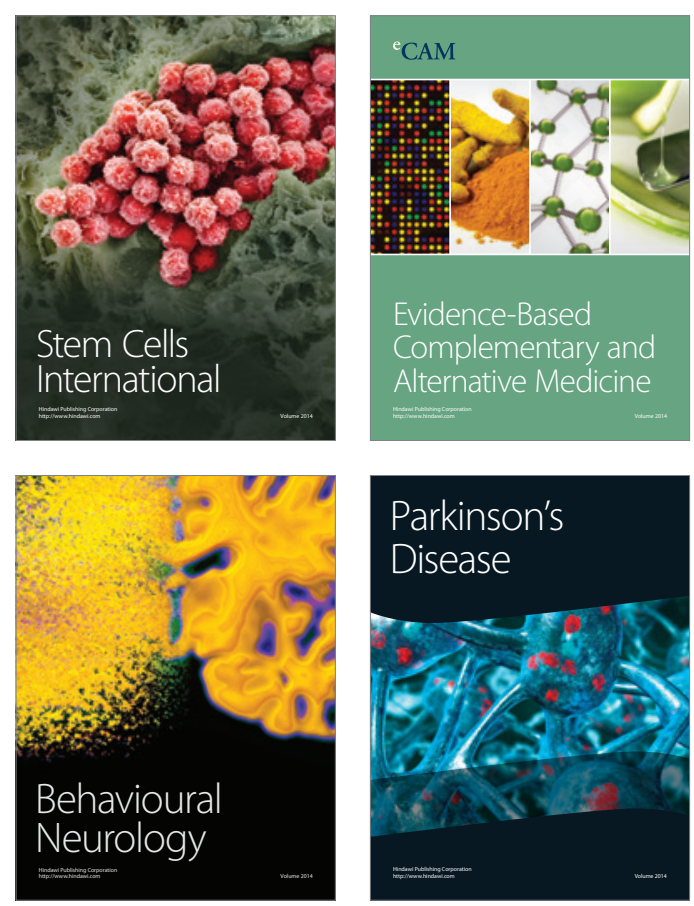

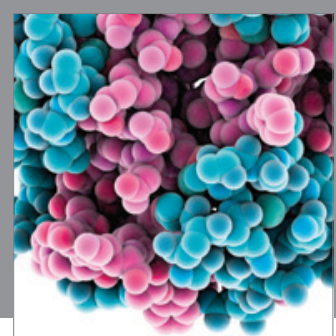

Journal of
Diabetes Research

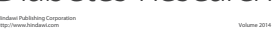

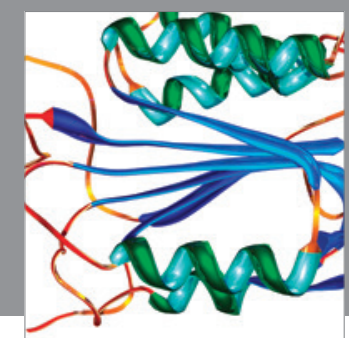

Disease Markers
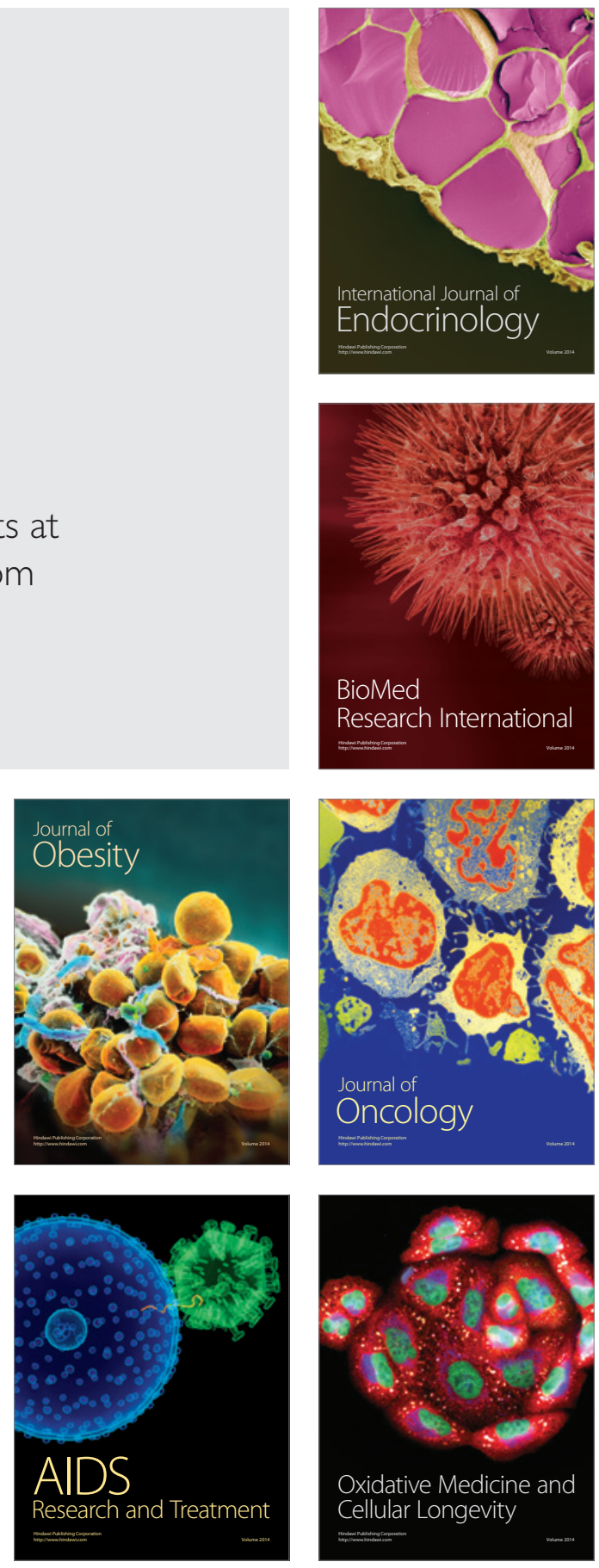